\title{
Prolyl isomerase Pin1 in cancer
}

\author{
Zhimin $\mathrm{Lu}^{1,2,3}$, Tony Hunter ${ }^{4}$ \\ ${ }^{I}$ Brain Tumor Center and Department of Neuro-Oncology, ${ }^{2}$ Department of Molecular and Cellular Oncology, ${ }^{3}$ Cancer Biology \\ Program, The University of Texas Graduate School of Biomedical Sciences at Houston, Houston, TX 77030, USA; ${ }^{4}$ Molecular and \\ Cell Biology Laboratory, Salk Institute for Biological Studies, La Jolla, CA 92037, USA
}

Proline-directed phosphorylation is a posttranslational modification that is instrumental in regulating signaling from the plasma membrane to the nucleus, and its dysregulation contributes to cancer development. Protein interacting with never in mitosis A1 (Pin1), which is overexpressed in many types of cancer, isomerizes specific phosphorylated Ser/Thr-Pro bonds in many substrate proteins, including glycolytic enzyme, protein kinases, protein phosphatases, methyltransferase, lipid kinase, ubiquitin E3 ligase, DNA endonuclease, RNA polymerase, and transcription activators and regulators. This Pin1-mediated isomerization alters the structures and activities of these proteins, thereby regulating cell metabolism, cell mobility, cell cycle progression, cell proliferation, cell survival, apoptosis and tumor development.

Keywords: Pin1; phosphorylation; cancer

Cell Research (2014) 24:1033-1049. doi:10.1038/cr.2014.109; published online 15 August 2014

\section{Introduction}

Protein phosphorylation orchestrates the activation of signaling cascades in response to extra- and intracellular stimuli to control cell growth, proliferation and survival. These signaling events often include conformational changes in protein kinases and their substrates. Such conformational changes represent spatially and temporally controlled signaling mechanisms that regulate a spectrum of protein activities in physiological processes and diseases such as cancer $[1,2]$. Conformational interconversions of the backbones of signaling proteins mediated by peptidyl prolyl cis-trans isomerization play a pivotal role in many aspects of cellular functions.

Proline-directed protein phosphorylation is a common and central signaling mechanism that has crucial roles in diverse cellular processes and controls cell proliferation and transformation, and its dysregulation contributes to many human cancers [3]. Enzymes that are responsible for such phosphorylation belong to a large superfamily of proline-directed protein kinases, which include cy-

Correspondence: Zhimin $\mathrm{Lu}^{\mathrm{a}}$, Tony Hunter ${ }^{\mathrm{b}}$

${ }^{a}$ Tel: 713-834-6231; Fax: 713-834-6230

E-mail: zhiminlu@mdanderson.org;

${ }^{\text {b } T e l: ~ 858-453-4100 ; ~ F a x: ~ 713-834-6230 ~}$

E-mail: hunter@salk.edu clin-dependent protein kinases (CDKs), mitogen-activated protein kinases (MAPKs), including extracellular signal-regulated kinases (ERKs), stress-activated protein kinases/c-Jun N-terminal kinases (SAPKs/JNKs), and p38 kinases, glycogen synthase kinase 3 (GSK3) and Polo-like kinases (PLKs) [4]. Proline exists in one of two distinct conformers, cis and trans. In peptides, proline interconversion occurs spontaneously and slowly in aqueous solution. Peptidyl prolyl cis/trans isomerases (PPIases) catalyze the cis-trans isomerization of peptidyl prolyl bonds, and this cis-trans rotation of the peptide bond affects the spatial arrangement of the backbone segments in the proteins. The three phylogenetically conserved PPIase families are cyclophilins, FK506-binding proteins and parvulins [5]. Protein interacting with never in mitosis A1 (Pin1), which is a member of the parvulin subfamily of PPIases and was originally identified in 1996 [6], specifically recognizes phosphorylated serine $(\mathrm{S})$ or threonine $(\mathrm{T})$ residues in $\mathrm{pSer} / \mathrm{Thr}$-Pro peptide sequences [6-9]. When a proline is positioned at the +1 position adjacent to a phosphorylated serine or threonine, the cis-trans conversion of the pSer/Thr-Pro bond is significantly more thermodynamically hindered than that of the Ser/Thr-Pro bond and rendered inaccessible to conventional PPIases, such as cyclophilins and FK506-binding proteins, but the $\mathrm{pSer} / \mathrm{Thr}$-Pro bond can be specifically recognized by Pin1 [5]. 


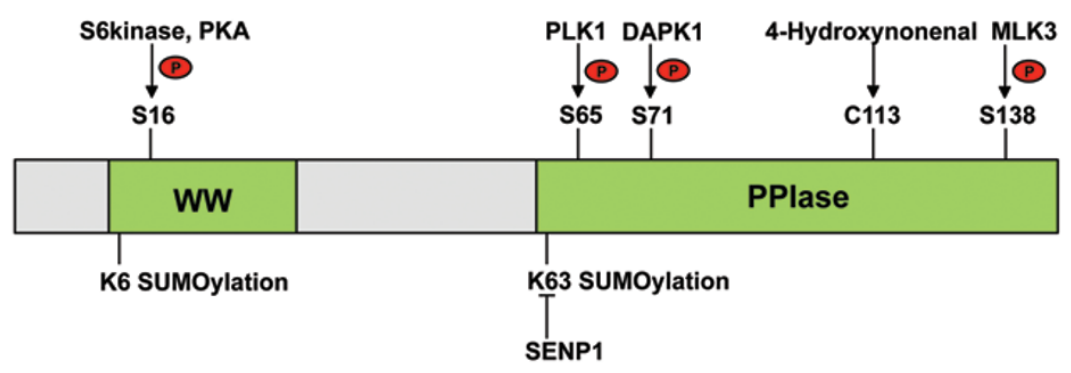

Figure 1 Schematic of the structure of Pin1 showing the regulatory posttranslational modification sites.

Pin1 has a modular domain architecture consisting of an N-terminal WW domain, a flexible linker and a C-terminal parvulin-type catalytic PPIase domain (Figure 1). The WW domain is responsible for Pin1's binding to pSer/Thr-Pro motifs in substrate proteins [5]. In addition, the Pin1 WW domain binds to the cis or trans, or both conformations of a pSer/Thr-Pro motif in a sequence-dependent manner [10]. For instance, the Pin1 WW domain exhibits almost the same affinity for the cis and trans conformations of the pThr668-Pro peptide of amyloid precursor protein and thus Pin 1 catalyzes the interconversion between both conformations [11].

Pin1-catalyzed cis-trans isomerization could define subsequent enzyme actions on the targets. For example, Pin1-dependent isomerization promotes the dephosphorylation of trans-phospho-Ser/Thr-Pro motifs in its substrate proteins Cde25C (pThr48-Pro and pThr67Pro motifs) and Tau (pThr231-Pro motif) by the serine/ threonine protein phosphatase 2A (PP2A) [12], while it promotes the dephosphorylation of the cis-phosphoSer5-Pro motif of RNA polymerase II C-terminal domain (CTD) by the protein phosphatase Ssu72 [13]. Structural analyses of protein phosphatase Ssu72 in complex with the phosphorylated RNA polymerase II CTD substrate reveal that the CTD peptide is bound to the active site of Ssu72 with the phospho-Ser5-Pro peptide bond in the cis configuration $[13,14]$. Pin1 isomerase activity greatly stimulates Ssu72 activity by increasing the pool of the CTD peptide in the cis configuration, which triggers the recruitment of Ssu72 and other transcription regulators to regulate general transcription. In contrast, small CTD phosphatase 1 (Scp1) binds to the trans-phospho-Ser5Pro motif of CTD, which serves as its dephosphorylation substrate, and Pin1 has limited effect on Scp1 activity. Scp1 and the REST complex are recruited to CTD with the trans-phospho-Ser5-Pro motif to inhibit neuronal gene expression [15]. These findings underscore the importance of Pin1's function in regulating the recruitment of isomer-specific phosphatases for dephosphorylation of the substrate proteins.

Pin1 can also regulate the stability of substrate proteins by increasing or decreasing their ubiquitylation. Pin1 works with different E3 ubiquitin ligases to regulate degradation of proteins. Examples include the Skp1Cullin-F-box (SCF)-type E3 ligase complexes for the degradation of c-Myc [16, 17] and cyclin E [18]; the suppressor of cytokine signaling (SOCS)1 (SOCS1 serves as the substrate-specific subunit of a Cullin 5 CRL E3 ligase complex, which is composed of Cul5, EloB/C and Rbx1) for the degradation of p65/RelA [19]; and HDM2 for the degradation of Che-1, an RNA polymerase II-binding protein that plays an important role in gene expression and the maintenance of the G2/M checkpoint [20].

Pin1 mediates conformational changes in its substrate proteins. However, some of Pin1's functions could be mediated simply by binding of its $\mathrm{WW}$ domain to $\mathrm{pS}$ / T-P motifs (i.e., a scaffolding activity) without involving its catalytic activities. To determine whether Pin 1 acts on a $\mathrm{pS} / \mathrm{T}-\mathrm{P}$ target protein in a catalytic activity-dependent manner, Nakamura et al. [21] devised a method for generating isomer-specific antibodies for detecting cis and trans $\mathrm{pS} / \mathrm{T}-\mathrm{P}$ bonds in a sequence-dependent manner. Such antibodies can be used to directly assess the cistrans isomerization state of individual $\mathrm{pS} / \mathrm{T}-\mathrm{P}$ bonds in vivo and provide evidence for their conformation-specific function or regulation [21].

Pin1 is regulated by extra- and intracellular stimuli, and governs the structures and functions of a broad range of signaling molecules, thus playing a pivotal role in tumor cell growth, survival, migration, invasion and metastasis. Mouse models have been used to investigate the critical roles of Pin1 in regulating tumor development. Transgenic overexpression of Pin 1 in mouse mammary glands induces centrosome duplication, chromosome missegregation and aneuploidy, and results in mammary hyperplasia and malignant mammary tumors [22]. In addition, Pin 1 ablation in mice is highly effective in preventing oncogenic Her2 or Ha-Ras from inducing cyclin 
D1 expression and mouse mammary gland carcinoma [23]. Furthermore, Pin1 ablation in p53-knockout mice inhibits p53 deficiency-induced formation of lymphomas [24]. These findings support an instrumental role of Pin1 in promoting tumor development. This review will discuss the mechanisms underlying Pin1 regulation and the effect of Pinl's regulation of its substrates in tumor development.

\section{Pin1 expression in human cancer}

Pin1 overexpression is prevalent in human cancers. Analyses of 60 different human tumor types revealed that 38 of these tumors, including prostate, breast, lung, ovary and cervical tumors, and melanoma, have Pin1 overexpression in more than $10 \%$ of cases, as compared with the corresponding normal control tissues. Consistent with these findings, Pin1 expression in several types of human cancer is frequently found to be higher than that in their normal counterparts $[25,26]$. Moreover, Pin1 expression has been linked to cancer prognosis. Two studies of Pin1 expression levels in 78 and 580 prostate tumor specimens, respectively, revealed that Pin 1 overexpression positively correlates with a higher probability of and a shorter time to tumor recurrence following radical prostatectomy [27, 28]. High Pin1 expression has also been reported to correlate with poor survival and lymph node metastasis in non-small cell lung cancer patients and with disease progression in oral squamous cell carcinoma patients [29-31]. Similarly, Pin1 overexpression in esophageal squamous cell carcinoma correlated with lymph node metastasis and poor prognosis, and was found to be an independent prognostic factor for the disease [30]. In addition, Pin 1 expression has been found to correlate with other tumor markers in humans. For example, Pin1 expression is associated with $\beta$-catenin accumulation in oral squamous cell carcinoma and closely correlates with cyclin D1 levels in esophageal squamous cell carcinoma and oral squamous cell carcinoma [30, 32, 33]. These findings support an important role for Pin1 in tumorigenesis and tumor progression.

\section{Pin1 regulation in cancer}

Pin 1 can be regulated both transcriptionally and posttranslationally. However, whether PIN1 is amplified in cancer has not been intensively studied. PIN1 is a direct target of E2 transcription factor 1 (E2F1), and Her2- and $\mathrm{H}$-Ras-oncogenic signaling upregulates Pin1 expression via E2F1 [34]. In tamoxifen-resistant breast cancer cells, the phosphatidylinositol 3-kinase (PI3K) and p38 MAPK-dependent activation of E2F1 is critical for Pin1 induction [35]. PIN1 promoter activity is decreased by a single-nucleotide polymorphism, $-842 \mathrm{G}>\mathrm{C}$ (rs2233678); this polymorphism has been associated with a decreased risk of squamous cell carcinoma of the head and neck [36, 37]. A different PIN1 promoter single-nucleotide polymorphism, rs2287839, which is located within the consensus binding motif for the brain-selective transcriptional repressor AP4, almost completely abolishes the ability of AP4 to bind to the PIN1 promoter and to suppress the PIN1 promoter transcriptional activity [38].

Pin1 activity can also be regulated post-translationally (Figure 1). Death-associated protein kinase 1 (DAPK1) phosphorylates Pin1 at S71 in the PPIase catalytic active site to inactivate Pin1's catalytic activity and inhibit Pin1's nuclear localization and cellular function [39]. In contrast, mixed-lineage kinase 3 (MLK3), a MAPK kinase kinase (MAP3K) family member, phosphorylates Pin1 at S138 in the PPIase domain to increase its catalytic activity and nuclear translocation [40]. In addition, PLK1-dependent phosphorylation of Pin1 at S65 in the PPIase domain, which prevents the ubiquitylation and proteasome-dependent degradation of Pin1 without affecting its isomerase activity, stabilizes Pin1 [41]. The binding of Pin 1 to its substrates can also be regulated by Pin 1 phosphorylation. For instance, 12-O-tetradecanoylphorbol-13-acetate (TPA) treatment results in an interaction between the $90-\mathrm{kDa}$ ribosomal protein $\mathrm{S} 6$ kinase 2 and Pin1, leading to the phosphorylation of Pin1 at S16 in the WW domain; this phosphorylation inhibits pSer/Thr-Pro target binding, thus regulating phosphoserine/threonine-binding activity of the WW domain and Pin1 function $[42,43]$. In addition, upon forskolin treatment, activated PKA phosphorylates Pin1 at S16 in the WW domain, which results in the removal of Pin1 from nuclear speckles and redistribution of Pin1 throughout the cell. Expression of a mutant Pin1 carrying the WW domain S16A mutation induces mitotic block and apoptosis, and increases multinucleated cells [42], indicating that Pin1 phosphorylation at S16 has an essential role in cell cycle progression.

Oxidative stress induces lipid electrophiles to target Pin1 for modification. 4-hydroxynonenal, a common product of oxidative damage to membrane lipids, disrupts Pin 1 activity by forming an adduct with Pin 1 at C113, a residue in the active site that is essential for catalytic activity. Pin 1 depletion partially protects breast cancer cells from 4-hydroxynonenal-induced toxicity [44].

SUMOylation is another regulatory modification for Pin1. SUMOylation of Pin1 on K6 in the WW domain and on K63 in the PPIase domain inhibits Pin1's activity and oncogenic function. SUMOylated Pin 1 can be deSUMOylated by SUMO protease 1 (SENP1), which increas- 
es Pin1 protein stability. Overexpression of SENP1 or disruption of Pin1 SUMOylation by mutations promotes Pinl's ability to induce centrosome amplification and cell transformation [45].

\section{Pin1 regulates glycolytic enzymes for the Warburg effect and cell cycle progression}

Pin1 plays a pivotal role in regulating the nuclear translocation of pyruvate kinase M2 (PKM2) and in subsequent regulation of the Warburg effect and cell cycle progression. The Warburg effect (also known as aerobic glycolysis) is characterized by elevated rates of glucose uptake and lactate production in tumor cells in the presence of oxygen; it enables tumor cells to function like fetal cells and use a large fraction of glucose metabolites to synthesize amino acids, phospholipids and nucleic acids that support tumor cell growth. PKM2, which catalyzes the final rate-limiting step of glycolysis by transferring a phosphate group from phosphoenolpyruvate (PEP) to adenosine diphosphate (ADP) to produce pyruvate and adenosine triphosphate (ATP), is instrumental in regulation of the Warburg effect [46, 47].

In response to activation of the epidermal growth factor (EGF) receptor (EGFR) and platelet-derived growth factor (PDGF) receptor, PKM2 translocates into the nucleus [48]. This translocation is mediated by the binding of ERK1/2 to PKM2 and phosphorylation of PKM2 at S37, which creates a binding motif for the Pin $1 \mathrm{WW}$ domain. The Pin1-dependent cis-trans isomerization of PKM2 dissociates the tetrameric PKM2 into monomers and exposes the inter- and/or intramolecularly masked nuclear localization sequence (NLS) encoded by PKM exon 10 , leading to recognition of the NLS by importin- $\alpha$ and subsequent PKM2 nuclear translocation [46, 48, 49].

In the nucleus, PKM2 interacts with $\beta$-catenin phosphorylated by c-Src at Y333, an interaction that is required for their coordinate binding to the promoter regions of $C C N D 1$ (encoding cyclin D1) and $M Y C$, where PKM2 phosphorylates histone $\mathrm{H} 3$ at $\mathrm{T} 11[48,50$, 51]. This phosphorylation disrupts the binding of histone deacetylase 3 to histone $\mathrm{H} 3$, which leads to histone H3K9 acetylation and the subsequent transcriptional activation of $C C N D 1$ and $M Y C[51,52]$. The increased expression of cyclin D1 promotes G1-S progression, whereas the enhanced expression of c-Myc upregulates expression of glycolysis-related proteins, including glucose transporter 1 (GLUT1) and lactate dehydrogenase A (LDHA), and polypyrimidine tract-binding protein (PTB) that facilitates the splicing of $P K M$ pre-mRNA into $P K M 2$ mRNA, thereby upregulating PKM2 expression [50]. The increased expression of these glycolysis-related proteins promotes glucose uptake and lactate production. Thus, the Pin1-dependent nuclear translocation of PKM2 and the subsequent nuclear PKM2-regulated expression of the c-Myc and cyclin D1 promote the Warburg effect and cell cycle progression [46] (Table 1).

\section{Pin1 regulates protein kinases and phosphatases}

Protein phosphorylation regulated by protein kinases and phosphatases is involved in every important cellular activity in eukaryotic cells [53]. Pin1 regulates the functions of protein kinases and phosphatases at the plasma membrane, cytosol and nucleus.

Pin1 regulates receptor protein tyrosine kinases, Notch and non-receptor protein tyrosine kinase and phospha-

Table 1 Selected Pin1 substrates

\begin{tabular}{lllll}
\hline Protein & $\begin{array}{l}\text { Substrate regulation by } \\
\text { Pin1 }\end{array}$ & Pin1-binding motif & $\begin{array}{l}\text { Kinase phosphorylating } \\
\text { Pin1 substrates }\end{array}$ & $\begin{array}{l}\text { Cellular consequence of } \\
\text { Pin1 activation }\end{array}$ \\
\hline $\begin{array}{llll}\text { Glycolytic enzyme } & & & \text { Ref. }\end{array}$ \\
PKM2 & $\begin{array}{l}\text { Promoting nuclear } \\
\text { translocation }\end{array}$ & S37 & ERK & $\begin{array}{l}\text { Promoting the Warburg } \\
\text { effect and cell cycle } \\
\text { progression }\end{array}$
\end{tabular}

Protein kinases and receptors

\begin{tabular}{llcl} 
Her2 & Increased stability & & $\begin{array}{l}\text { Increased tumor cell growth } \\
\text { and chemoresistance }\end{array}$ \\
Notch1 & $\begin{array}{l}\text { Protein cleavage for } \\
\text { activation, increased } \\
\text { stability }\end{array}$ & T2512 & Increased gene transcription $\quad$ [55, 56] \\
& & \\
\hline
\end{tabular}




\begin{tabular}{|c|c|c|c|c|c|}
\hline$\overline{\text { FAK }}$ & $\begin{array}{l}\text { FAK Y397 } \\
\text { dephosphorylation }\end{array}$ & S910 & ERK & $\begin{array}{l}\text { Increased tumor cell } \\
\text { migration, invasion, } \\
\text { and metastasis }\end{array}$ & [57-59] \\
\hline Raf-1 & Dephosphorylation & $\begin{array}{l}\text { S29, S289, S296, } \\
\text { S301 and S642 }\end{array}$ & ERK & Raf- 1 activation & {$[62]$} \\
\hline JNK1 & $\begin{array}{l}\text { Activation by inhibiting } \\
\text { dephosphorylation }\end{array}$ & $\mathrm{T} 183$ & & Increased apoptosis & {$[64]$} \\
\hline AKT & Increased stability & T92, T450 & & Increased tumor growth & {$[65]$} \\
\hline P70S6K & Increased activity & & & Increased cell transformation & {$[66]$} \\
\hline GRK2 & Degradation & S670 & CDK2 & $\begin{array}{l}\text { Cell cycle progression, } \\
\text { cell survival regulation }\end{array}$ & {$[67]$} \\
\hline CDK10 & $\begin{array}{l}\text { Ubiquitylation and } \\
\text { degradation }\end{array}$ & $\mathrm{T} 133$ & & $\begin{array}{l}\text { Activation of Raf/ERK } \\
\text { MAPK pathway }\end{array}$ & {$[74]$} \\
\hline
\end{tabular}

Protein phosphatases

$\begin{array}{lllll}\text { PTP-PEST } & \begin{array}{l}\text { Dephosphorylation } \\ \text { of FAK Y397 }\end{array} & \text { S571 } & \text { ERK } & \text { [60, 61] } \\ \text { CDC25 } & \begin{array}{l}\text { Activating CDC2/ } \\ \text { cyclin B }\end{array} & \text { T48, T67 } & \begin{array}{l}\text { Tumor cell migration, } \\ \text { invasion, and metastasis }\end{array} & \text { Cell cycle progression } \\ & & & 69,71]\end{array}$

RNA polymerase

$\begin{array}{llll}\text { RNA } & \text { Dephosphorylation } & \text { S5 } & \text { Transcription progression } \\ \text { polymerase II } & \text { by Ssu72 } & & 14,15]\end{array}$

Methyltransferase

$\begin{array}{lll}\text { SUV39H1 Protein ubiquitylation, } & \text { S391 } \\ \text { degradation } & & \begin{array}{l}\text { Reduced H3K9me3 and } \\ \text { enhanced gene expression }\end{array}\end{array}$

Lipid kinase

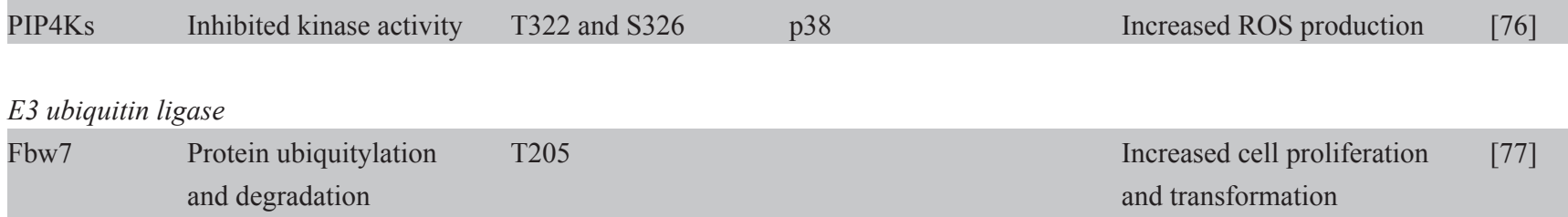

DNA endonuclease

$\begin{array}{llll}\text { RBBP8 } & \begin{array}{l}\text { Protein ubiquitylation, } \\ \text { degradation }\end{array} & \text { S276 and T315 } & \text { Inhibited DNA end resection }\end{array}$

Transcription factors and co-regulators

Transcription regulators promoting tumorigenesis

\begin{tabular}{|c|c|c|c|c|c|}
\hline Cyclin D1 & Increased stability & T286 & GSK3 $\beta$ & Increased gene transcription & {$[81]$} \\
\hline Cyclin E & Degradation & S384 & CDK2 & $\mathrm{G} 1 / \mathrm{S}$ arrest & {$[18,78]$} \\
\hline$\beta$-catenin & Increased stability & S246 & & Increased gene expression & {$[82]$} \\
\hline c-Fos & $\begin{array}{l}\text { Hetero-dimerization with } \\
\text { other transcription factors }\end{array}$ & $\begin{array}{l}\text { T232, Т325, Т331, } \\
\text { and S374 }\end{array}$ & ERK & Increased gene expression & {$[84]$} \\
\hline RelA & Increased stability & $\mathrm{T} 254$ & & Increased gene expression & [19] \\
\hline
\end{tabular}




\begin{tabular}{|c|c|c|c|c|c|}
\hline $\mathrm{c}-\mathrm{Myc}$ & $\begin{array}{l}\text { Promoter binding, and } \\
\text { subsequent c-Myc } \\
\text { degradation }\end{array}$ & T58, S62 & ERK, CDK, GSK3 $\beta$ & Gene expression & $\begin{array}{l}{[16,17,} \\
87,88]\end{array}$ \\
\hline c-Myb & $\begin{array}{l}\text { Increased transactivation } \\
\text { activity }\end{array}$ & S528 & & Increased gene expression & {$[90]$} \\
\hline SF-1 & $\begin{array}{l}\text { Increased SF-1-Pitx1 } \\
\text { interaction }\end{array}$ & S203 & & Increased gene expression & [91] \\
\hline
\end{tabular}

Transcription factors in regulation of stem cells

$\begin{array}{llll}\text { STAT3 } & \begin{array}{l}\text { Increased association } \\ \text { with p300 }\end{array} & \mathrm{S} 727 & \begin{array}{l}\text { Increased gene expression, } \\ \text { increased epithelial- } \\ \text { mesenchymal transition }\end{array} \\ \text { Nanog } & \text { Increased stability } & \mathrm{S} 52, \mathrm{~S} 65, \mathrm{~S} 71, & \begin{array}{l}\text { Stem cell renewal, } \\ \text { and T287 }\end{array} \\ \text { tumor formation }\end{array}$

Nuclear receptor

\begin{tabular}{|c|c|c|c|c|c|}
\hline $\mathrm{ER} \alpha$ & $\begin{array}{l}\text { Increased dimerization, } \\
\text { stability, and activity }\end{array}$ & S118, S294 & CDK2, ERK & Increased gene expression & [98- \\
\hline
\end{tabular}

Transcription regulators in tumor suppression

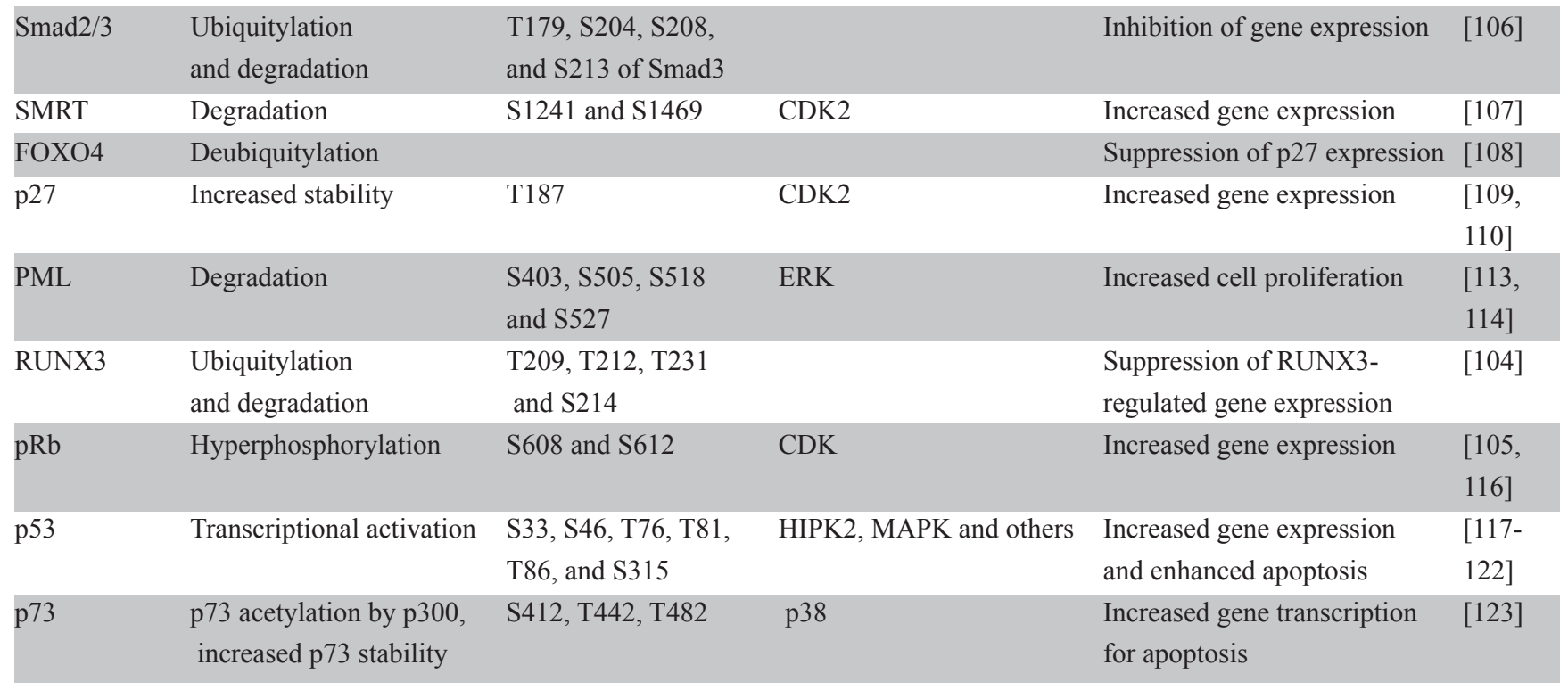

Apoptotic proteins

$\begin{array}{lllll}\text { BAX } & \begin{array}{l}\text { Suppressed cleavage and } \\ \text { mitochondrial translocation } \\ \text { of BAX }\end{array} & \text { T167 } & \text { ERK } & \text { Anti-apoptosis } \\ \text { Daxx } & \begin{array}{l}\text { Ubiquitylation and } \\ \text { degradation }\end{array} & \text { S178 } & & \text { Anti-apoptosis } \\ \text { Bcl-2 } & \text { Phosphorylation } & \text { S70 and S87 } & & \text { Apoptosis regulation } \\ \text { Mcl-1 } & \text { Increased stability } & \text { T92 and T163 } & \text { ERK } & \text { A126, } \\ \text { Survivin } & \begin{array}{l}\text { Interaction with } \\ \text { pro-caspase-9 }\end{array} & \text { T34 } & \text { CDC2 } & \text { Anti-apoptosis } \\ & & & {[129]}\end{array}$


tase at the plasma membrane

Pin1, which is highly expressed in Her2-positive breast cancer, interacts with the protein complex that contains ubiquitylated Her2. Pin1 depletion, which accelerates Her2 degradation, significantly suppresses the growth of Her2-positive tumor cells and sensitizes these tumor cells to the mammalian target of rapamycin (mTOR) inhibitor rapamycin [54].

Notch receptor signaling requires ligand-induced proteolytic cleavage to release the intracellular domain of Notch, which acts as a transcriptional activator in the nucleus. Deregulated Notch1 signaling has been implicated in mammary tumorigenesis, including breast cancer development. Pin 1 binds to phosphorylated Notch1 and potentiates Notch1 intramembrane cleavage by $\gamma$-secretase, which increases the release of the active intracellular domain and enhances the activity of Notch1 in regulation of gene transcription [55]. In addition, Pin1 binds to phosphorylated T2512/P2513 within the Cdc4-phosphodegron of Notch1 and Notch 4, which is a motif known to be recognized by SCF-Fbw7 $\alpha$ upon phosphorylation of T2512. Pin1-regulated prolyl-isomerization of the Notch proteins results in dephosphorylation of Notch1 and Notch4 by the PP2A phosphatase, preventing Fbw $7 \alpha$ interaction and subsequent polyubiquitylation and degradation of Notch1 and Notch4. The Pin1-mediated activation of Notch1 and Notch4 promotes the self-renewal and chemoresistance of breast cancer stem cells, as well as tumor growth and metastasis formation [56]. Intriguingly, the distal BS1 element on the PIN1 promoter is directly regulated by Notch1 signaling; thus, these two factors form a feed-forward loop. The mutual regulation of these two proteins in cancer is supported by a strong correlation between Pin 1 overexpression and high levels of activated Notch1 in human breast cancer specimens [55].

Focal adhesion kinase (FAK) is a focal adhesion-associated non-receptor protein-tyrosine kinase involved in cellular adhesion and spreading and cell migration. Activation of EGFR and Ras, which has been detected in many types of human cancer and found to promote tumor cell migration and metastasis, induces FAK Y397 dephosphorylation and FAK inhibition, a process mediated by the Ras downstream Cdc42-p21-activated kinase 1 (PAK1)-MAPK kinase (MAP2K) (MEK)-ERK signaling cascade [57-59]. ERK phosphorylates FAK at S910 and the protein-tyrosine phosphatase (PTP)-proline-, glutamate-, serine- and threonine-rich sequence (PEST) at S571, leading to the recruitment of Pin1 and PTPPEST to colocalize with FAK at the lamellipodia of migrating cells. Pin1 binding and the prolyl isomerization of both FAK and PTP-PEST cause PTP-PEST to interact with and dephosphorylate FAK Y397. FAK inhibition mediated by Pin1-dependent, PTP-PEST-regulated FAK Y397 dephosphorylation promotes the disassembly of focal adhesions and the turnover of lamellipodia and enhances Ras-induced cell migration, invasion and metastasis [58-61].

Pin1 regulates cytosolic protein kinases in the MAPK and AKT pathways

The Raf-1 kinase, an important signaling molecule at the top of the ERK MAPK pathway, functions in the Ras pathway to transmit mitogenic, differentiative and oncogenic signals to the downstream kinases MEK and ERK. Activated ERK phosphorylates Raf-1 at S29, S289, S296, S301 and S642 to block the interaction between Ras and Raf-1, thereby inhibiting Raf-1 activity via a negative feedback mechanism. The hyperphosphorylated and desensitized Raf-1 subsequently undergoes cis-trans isomerization by Pin1, which leads to Raf-1's dephosphorylation by PP2A, and this dephosphorylation returns Raf-1 to a signaling-competent state. Deficiency or inhibition of Pin1 blocks PDGF-induced Raf-1 activation, indicating that Pin 1 is required for Raf- 1 to be recycled for activation after PDGF stimulation, as it is required for PP2A dephosphorylation of Raf-1 at the ERK phosphorylation sites [62]. In contrast, in response to EGF stimulation, Pin1 does not interact with Raf-1 but instead interacts with MEK1. This interaction enhances the EGF-induced phosphorylation of MEK1/2 and ERK1/2 and induces activator protein (AP)2-dependent Her-2 expression, which in turn promotes neoplastic cell transformation [63]. In contrast to ERK, which is indirectly regulated by Pin1 through Pin1 action on ERK-upstream protein kinases, JNK1 (another member of the MAPK family) is directly regulated by Pin1. In response to hydrogen peroxide stimulation, Pin 1 binds to the phosphorylated T183 of JNK1 in the activation loop and catalyzes the isomerization of the phospho-T183-Pro motif from trans to cis conformation. This structural change stabilizes JNK1 activity by inhibiting PP2A-dependent JNK1 dephosphorylation, thus enhancing the interaction between JNK1 and its substrates, such as c-Jun and activating transcription factor (ATF)2, increasing the binding of T-cell factor (TCF) $\beta 1$ to the interleukin-2 (IL-2) promoter to induce IL-2 production and enhancing JNK1-induced apoptosis [64].

In addition to the MAPK pathways, AKT-regulated signaling is another central regulatory pathway in many cellular functions. Pin1 regulates AKT stability and phosphorylation at S473. Pin1 binds to the phosphorylated Thr-Pro motifs at AKT T92 and T450 (the "turn motif"), and this binding is required for the maintenance of $\mathrm{AKT}$ 
stability and AKT phosphorylation at S473. Pin1 deficiency or depletion by its shRNA compromises Pin1's ability to protect AKT from degradation. In addition, expression levels of Pin 1 and levels of AKT phosphorylation at S473 have been found to be strongly correlated in multiple cancer types. In breast cancer patients, the combination of high AKT-pS473 levels with high Pin1 expression levels predicts poorer prognosis than either factor alone [65].

p70 ribosomal protein S6 kinase (p70S6K), which is downstream of AKT/mTOR signaling, also binds to Pin1 in a p70S6K phosphorylation-dependent manner. In hepatocarcinoma cells, this complex formation enhances the phosphorylation of p70S6K at T389, the activity of p70S6K and the interaction between p70S6K and ERK $1 / 2$ in response to insulin stimulation, thereby increasing ERK1/2 activity, AP1 transactivation activity and neoplastic cellular transformation [66]. These results suggest that Pin1 plays an important role in insulin-promoted hepatocarcinoma tumorigenesis.

Pin1 modulates protein kinase and phosphatase actions in cell cycle regulation

Cell cycle progression requires orchestrated changes in the activity or expression levels of a variety of key signaling proteins. $\mathrm{G}$ protein-coupled receptor kinase 2 (GRK2), which plays a central role in G protein-coupled receptor regulation, is phosphorylated by the cyclin-dependent kinase 2 (CDK2) at S670 near the C-terminus. This phosphorylation triggers GRK2's binding to Pin1 and its subsequent degradation during the G2/M transition. Prevention of GRK2 phosphorylation at S670 by mutation to Ala impedes normal GRK2 downregulation and markedly delays cell cycle progression in a receptor-independent fashion [67]. In addition, doxorubicin-induced activation of the G2/M checkpoint stabilizes GRK2 levels, which inversely correlate with the p53 response and the induction of apoptosis, suggesting that GRK2 participates in the regulatory network that controls cell cycle arrest and survival under such conditions [67].

The cyclin-dependent kinase CDC2 (the human homolog of CDK1)/cyclin B complex regulates mitosis entry and progression. $\mathrm{CDC} 2$ is negatively regulated by phosphorylations at its T14 and Y15 residues, which are mediated by the Myt1 and Weel kinases, respectively. These phosphorylations can be reversed by the CDC25 phosphatase. Pin 1 interacts with Myt1 in a phosphorylation-dependent manner and potentially modulates Myt1-regulated mitosis entry [68]. In addition, Pin1 interacts with CDC25 and PLK1, a CDC25-regulatory serine/threonine-protein kinase that phosphorylates the amino-terminal domain of CDC25 $[69,70]$. The interaction between Pin 1 and phosphorylated CDC 25 promotes a conformational change in $\mathrm{CDC} 25$ and increases its ability to activate and maintain $\mathrm{CDC} 2 /$ cyclin $\mathrm{B}$ activity $[69,71]$. These results suggest that Pin 1 modulates cell cycle control through its interaction with $\mathrm{CDC} 25$ and its regulation of $\mathrm{CDC} 25$-dependent $\mathrm{CDC} 2 /$ cyclin $\mathrm{B}$ activity.

Pin1 also regulates CDK10, which uses cyclin $M$ as an activating cyclin. Cyclin M/CDK10 phosphorylates the transcription factor ETS2 and causes ETS2 degradation by the proteasome [72]. CDK10 depletion increases the activity of the transcription factor ETS2 to induce expression of the RAF1 gene, resulting in ERK MAPK pathway activation [73]. Pin1 interacts with pT133 of CDK10, leading to the ubiquitylation and degradation of CDK10 [74]. Overexpression of CDK10 sensitizes tamoxifen-resistant breast cancer cells to 4-hydroxytamoxifen treatment [74].

\section{Pin1 regulates suppressor of variegation 3-9 homo- $\log 1$ methyltransferase (SUV39H1)}

One of the most abundant and stable histone modifications is the methylation of histone $\mathrm{H} 3$ on $\mathrm{K} 9$ (H3K9), which is involved in both gene repression and heterochromatin formation. Suppressor of variegation 3-9 homolog 1 (SUV39H1) is a major methyltransferase responsible for histone $\mathrm{H} 3 \mathrm{~K} 9$ trimethylation (H3K9me3). Pin1 interacts with the Ser391-Pro motif of SUV39H1 in a phosphorylation-dependent manner and promotes the ubiquitylation-mediated degradation of SUV39H1, which reduces H3K9me3 levels. Pin1 depletion elevates SUV39H1 expression, increases H3K9me3 levels and inhibits cancer cell tumorigenicity. In addition, SUV39H1 overexpression abrogates Pin1 overexpression-promoted tumor growth, and in human breast cancer specimens Pin1 levels have been found to be negatively correlated with SUV39H1 and H3K9me3 levels [75].

\section{Pin1 regulates lipid kinase, ubiquitin E3 ligase and DNA endonuclease}

Phosphatidylinositol-5-phosphate (PtdIns5P) 4-kinase (PIP4K) is a lipid-modifying enzyme that phosphorylates and thereby reduces the amount of PtdIns5P by converting it into phosphatidylinositol 4,5-bisphosphate. PIP4KPin1 interaction, which depends on the p38-mediated phosphorylation of PIP4K at T322 and S326, has been found to inhibit PIP4K activity in vitro. However, whether Pin1-mediated inhibition of PIP4K occurs in cells remains unknown. Compared with $P$ in $1^{+/+}$mouse embryonic fibroblasts (MEFs), Pin1 $1^{-/}$MEFs had higher PtdIn- 
s5P levels in response to hydrogen peroxide and higher expression of the genes required to eliminate reactive oxygen species (ROS), which increased the anti-oxidative ability and survival of these cells. Reducing the amount of PtdIns5P in Pin1 ${ }^{-/}$MEFs decreased the expression of these genes and increased the accumulation of cellular ROS, suggesting that Pin1 regulates PtdIns5P, a redox second messenger that alters gene expression to calibrate cells' sensitivity to ROS [76].

The F-box protein Fbw7, which has three alternatively spliced $\alpha, \beta$ and $\gamma$ isoforms, and binds to phosphorylated targets, is the substrate recognition component of an SCF E3 ligase complex and a tumor suppressor that targets oncoproteins such as cyclin E. Pin1 interacts with Fbw7 phosphorylated at T205 and disrupts Fbw7 dimerization to promote Fbw7 self-ubiquitylation and degradation. Fbw7 abundance inversely correlates with Pin1 expression in human colon cancer specimens, and Pin1 overexpression reduces Fbw7 abundance and promotes cell proliferation and transformation [77]. In addition to regulating Fbw7 abundance and the subsequent Fbw7-dependent degradation of its substrate proteins, Pin1 regulates the interaction between Fbw7 and phosphorylated cyclin E, Notch $1 / 4$ and c-Myc by altering the local conformation of these oncoproteins, and thus modulating their polyubiquitylation and degradation $[17,56,78]$. These findings suggest that Pin1 could manipulate Fbw7 functions and in doing so contribute to oncogenesis through multiple mechanisms, including Pin1-mediated Fbw7 degradation, disruption of Fbw7-mediated oncoprotein degradation due to reduced Fbw7 levels and interruption of the association between Fbw7 and these oncoproteins.

DNA endonuclease retinoblastoma-binding protein 8 (RBBP8), also known as C-terminal binding protein interacting protein (CtIP), cooperates with the MRE11RAD50-NBS1 complex in the processing of meiotic and mitotic double-strand breaks. Pin1 interacts with CtIP phosphorylated at S276 and T315 in a CDK2 activity-dependent manner. Pin1 isomerizes CtIP and promotes its ubiquitylation and degradation. CtIP phosphor-mutant expression promotes the hyper-resection of DNA double-strand breaks, supporting the notion that Pin1-dependent CtIP isomerization is a key regulatory mechanism that restricts the resection of DNA double-strand breaks in late $\mathrm{S} / \mathrm{G} 2$ phase [79].

\section{Pin1 regulates transcription factors}

Pin1 regulates transcription factors and transcription regulators including cyclin D1, cyclin E and c-Myc in central pathways important for tumor development

Cyclin D1, which is important for cell cycle progres- sion and cell proliferation, is a direct substrate of Pin1. Pin1 binds to cyclin D1 phosphorylated at Thr286-Pro by GSK $3 \beta$ and increases cyclin D1 levels in the nucleus and stabilizes cyclin D1. Pin1-deficient mice and cyclin D1-deficient mice share characteristics that include retinal hypoplasia and impaired mammary gland development. In pregnant Pin1-deficient mice, cyclin D1 levels are significantly reduced in many tissues, including the retina and breast epithelium, and these mice fail to undergo the massive proliferative changes in breast epithelium associated with pregnancy $[80,81]$.

Pin1 regulates cyclin D1 function not only at the posttranslational level but also at the transcriptional level through transcription factors, such as $\beta$-catenin, c-Jun and $\mathrm{p} 65 /$ RelA nuclear factor- $\mathrm{kB}(\mathrm{NF}-\mathrm{\kappa B})$ subunit, which upregulate $C C N D 1$ transcription [3, 19, 26, 82, 83]. Pin1 binds to the phosphorylated Ser246-Pro motif of $\beta$-catenin, which lies next to the adenomatous polyposis coli protein (APC)-binding site, thus inhibiting $\beta$-catenin's interaction with APC and increasing $\beta$-catenin's stability and its translocation into the nucleus. Pin1 increases the transcription of $\beta$-catenin target genes, thereby enhancing cyclin D1 and c-Myc expression. In addition, $\beta$-catenin expression levels are decreased in Pin1-deficient mice but increased and correlated with Pin1 overexpression in human breast cancer [82]. In response to the activation of JNK or oncogenic Ras, Pin1 binds to c-Jun phosphorylated at Ser63/73-Pro motifs in the transactivation domain by JNK and inhibits c-Jun ubiquitylation to increase its stability, thereby enhancing the transcriptional activity of c-Jun towards the cyclin D1 promoter [26, 83]. In addition, ERK phosphorylates multiple residues, including T232, T325, T331 and S374, within the C-terminal transactivation domain of c-Fos, which can heterodimerize with c-Jun or other AP1 family members. Pin1 binds to phosphorylated c-Fos, enhancing c-Fos's transcriptional response to polypeptide growth factors that stimulate ERK [84]. Cyclin D1 can also be upregulated by NF$\kappa \mathrm{B}$ activation. In response to cytokine stimulation, Pin1 binds to the phospho-Thr254-Pro motif in p65/RelA and inhibits the binding of p65/RelA to the NF- $\kappa B$ inhibitor $\mathrm{I} \kappa \mathrm{B} \alpha$, which increases the nuclear accumulation and stability of p65/RelA by inhibiting SOCS1-dependent ubiquitylation of p65/RelA, leading to enhanced NF- $\mathrm{kB}$ activity [19]. Pin 1 markedly enhances the transformation of primary lymphocytes by the human c-Rel protein and increases cell transformation by the potent viral oncoprotein v-Rel [85]. Thus, Pin1 regulates the expression levels of cyclin D1 and its regulators $\beta$-catenin, c-Jun and p65/RelA NF-kB, which also affect the expression of a broad spectrum of downstream genes to influence many important cellular activities. 
Besides regulating cyclin D1 expression, Pin1 also regulates the stability of cyclin E. Pin1's binding to the cyclin E-CDK2 complex depends on CDK2-mediated phosphorylation of cyclin E at S384 [18], which promotes cyclin $\mathrm{E}$ degradation mediated by the sequential functions of SCF-Fbw $7 \alpha$ and SCF-Fbw $7 \gamma$. First, SCF-Fbw $7 \alpha$ binds to a complex containing cyclin E, CDK2 and Pin1, and promotes the activity of Pin 1 to isomerize a non-canonical proline-proline bond in cyclin E (the P381-P382 bond), but does not directly ubiquitylate cyclin E. Pin1-mediated cyclin E isomerization leads to the release of cyclin E from SCF-Fbw7a, which enables SCF-Fbw $7 \gamma$ to bind to and polyubiquitylate cyclin E [78]. Fbw7-driven cyclin E degradation is impaired in cells expressing oncogenic RasG12V. Oncogenic Ras activity both inhibits cyclin E-Fbw7 binding and cyclin E ubiquitylation, and potentiates cyclin E-induced genetic instability, which may serve as a mechanism through which Ras mutations promote tumorigenesis [86].

In addition to regulating c-Myc expression by enhancing $\beta$-catenin transactivation [82], Pin 1 directly binds to c-Myc phosphorylated at S62 by ERK or CDK and promotes the recruitment of c-Myc and its coactivators, including histone acetyltransferases GCN5 and p300, to target gene promoters [87]. Subsequent removal of c-Myc from the promoters is mediated by GSK3 $\beta$-dependent c-Myc phosphorylation at T58. This in turn leads to Pin1-mediated c-Myc isomerization, which facilitates c-Myc S62 dephosphorylation by PP2A and subsequent recognition of c-Myc phosphorylated at T58 by SCFFbw7 for proteasomal degradation [16, 17, 87, 88]. Thus, through the binding of Pin1 to c-Myc phosphorylated at either S62 or T58, Pin1 is involved in both the recruitment and dissociation of c-Myc to and from target gene promoters. The tumor suppressor scaffold protein Axin1 is required for the formation of the degradation complex for c-Myc, containing GSK3 $\beta$, Pin1 and PP2A [89]. In some cancer cells in which the degradation of c-Myc is impaired due to Axin1 loss [87], c-Myc stabilization and Pin1-enhanced c-Myc DNA binding promote oncogenesis [87]. These findings show that in cancer cells Pin1-mediated activation of c-Myc could be uncoupled from its ability to promote c-Myc degradation.

Pin 1 also regulates the $\mathrm{c}-\mathrm{Myb}$ protein in a $\mathrm{c}-\mathrm{Myb}$ S528 phosphorylation-dependent manner and enhances its transactivation activity [90]. In addition, Pin1 activates SF-1, Pitx1 and Egr-1 transcription factors, either by modulating their stability or by increasing their protein-protein interactions. For instance, Pin 1 is required for the S203 phosphorylation-dependent ubiquitylation of SF-1, which facilitates the interaction between SF-1 and Pitx1, and therefore enhances SF-1 transcriptional activity [91]. Thus, Pin1 regulates a broad range of transcription factors in central pathways that are important for tumor development.

Pin1 regulates transcription factors involved in stem cell self-renewal and pluripotency

Pin1 knockout mice display some abnormalities owing to decreased cell proliferation, including decreased body weight, retinal degeneration, a neurodegenerative condition reminiscent of Alzheimer's disease and impaired mammary gland development $[80,92]$. These mice also exhibit testicular atrophy with significantly impaired proliferation of primordial germ cells and the progressive loss of spermatogenic cells [93], suggesting that the loss of Pin1 function causes impaired maintenance and proliferation of germ-related stem cells.

Prominent characteristics of pluripotent stem cells are their unique capacity to self-renew and their pluripotency. The activation of signal transducer and activator of transcription 3 (STAT3), Nanog and Oct4 plays instrumental roles in these processes [94-96]. STAT3 belongs to a family of latent cytoplasmic transcription factors important for tumor progression. In response to cytokine or growth factor stimulation, Pin1 recognizes phospho-Ser727-Pro of STAT3, leading to the binding of transcriptional coactivator p300 to STAT3, and thereby promotes STAT3 transcriptional activity and target gene expression to enhance STAT3-mediated epithelial-mesenchymal transition of breast cancer cells [96].

Nanog, a transcription factor crucial for the self-renewal of embryonic stem cells, is phosphorylated at multiple Ser/Thr-Pro motifs (i.e., S52, S65, S71 and T287). This phosphorylation promotes the interaction between Nanog and Pin1. Pin1 stabilizes Nanog by suppressing its ubiquitylation. In immunodeficient mice, inhibition of Pin1 activity or disruption of Pin1-Nanog interaction suppresses embryonic stem cells' capability to self-renew and form teratomas [95].

The fact that Pin 1 is indispensable for the self-renewal and maintenance of pluripotent stem cells is also demonstrated by its regulation of phosphorylated Oct4. Pin1 interacts with the phosphorylated Ser12-Pro motif of Oct4 and increases Oct4 stability and transcriptional activity. The induction of induced pluripotent stem (iPS) cells upregulates Pin1 expression, which in turn further enhances the frequency of iPS cell generation. Inhibition of Pin1 activity significantly suppresses the colony formation and induces the aberrant differentiation of human iPS cells and murine ES cells [94]. Thus, Pin1 promotes the induction and maintenance of pluripotency through its regulation of STAT3, Nanog and Oct4. 


\section{Pin1 regulates nuclear receptors}

Estrogen receptor- $\alpha(E R \alpha)$, a nuclear receptor expressed in breast epithelial cells, functions as a hormone-regulated transcription factor. Activation of the PI3K pathway promotes the nuclear translocation of CDK2 and phosphorylation of CDK2 at T160 in activation site [97]. Activated CDK2 in turn phosphorylates $\mathrm{ER} \alpha$ at S294 and mediates Pin1-ER $\alpha$ interaction, which increases ERK-dependent ER $\alpha$ phosphorylation at S118 and S167 in the transcriptional activation function domain and promotes ER $\alpha$ dimerization and activity [98, 99]. Pin 1 has also been shown to bind to ER $\alpha$ pS118 directly and cause the cis-trans isomerization of the pS118-P119 bond of ER $\alpha$. This isomerization stabilizes $\mathrm{ER} \alpha$ protein by blocking $\mathrm{ER} \alpha$ interaction with the E3 ligase, E6AP, and thus inhibiting the E6AP-mediated ubiquitylation and degradation of ER $\alpha$. In addition, Pin1 and ER $\alpha$ levels are positively correlated in human breast carcinoma specimens $[100,101]$.

Pin1 also promotes the activation of nuclear receptor-regulated transcription by interacting selectively with phosphorylated steroid receptor coactivator 3 (SRC-3/ AIB1/pCIP) and modulating interactions between SRC3 and cyclic adenosine monophosphate response element binding protein (CREB)-binding protein (CBP)/p300 coactivators [102].

Pin1 regulates transcription factors and co-regulators involved in tumor suppression and growth inhibition

In addition to transcription regulators that promote tumorigenesis, Pin1 also regulates a large number of tumor suppressors and growth inhibitors, including Smad transcription factors, the co-repressor silencing mediator for retinoic acid and thyroid hormone receptor (SMRT), forkhead box O (FOXO), promyelocytic leukemia protein (PML), runt-related transcription factor 3 (RUNX3), the retinoblastoma protein $(\mathrm{pRb}), \mathrm{p} 53$ and $\mathrm{p} 73[3,103-$ $105]$. Disruption of transforming growth factor- $\beta$ (TGF- $\beta$ ) signaling, which is crucial in numerous cellular processes including proliferation, differentiation, migration and apoptosis often occurs in cancer. Pin1 interacts with Smad2 and Smad3. Phosphorylation of (S/T)Pro motifs (T179, S204, S208 and S213) in the Smad3 linker region enhances the interaction between Pin 1 and Smad2/3, and the interaction of Smad2/3 with the ubiquitin E3 ligase Smurf2, which leads to enhanced Smad ubiquitylation and proteasomal degradation, thus inhibiting TGF- $\beta$-induced transcription and gene expression [106].

SMRT is a transcriptional co-repressor that participates in diverse signaling pathways and is involved in human diseases. Her2 activation decreases SMRT stability in a CDK2- and Pin1-dependent manner. CDK2 phos- phorylates SMRT at multiple sites (including S1241 and S1469). SMRT phosphorylation, which is required for Pin1 binding, decreases SMRT stability, thereby affecting SMRT-dependent transcriptional repression. Tamoxifen treatment of breast cancer cells repressed the expression of both c-Myc and the progesterone receptor; knockdown of SMRT expression compromised this repression, whereas depletion of Pin 1 or CDK2 enhanced the repression of both genes [107].

The FOXO protein family, an evolutionarily conserved subclass of transcription factors, is a family of tumor suppressors. Oxidative stress induces the binding of Pin1 to FOXO4 phosphorylated at multiple S/T residues and attenuates FOXO4 monoubiquitylation, in a manner mediated by the deubiquitylating enzyme HAUSP/ USP7. Pin1-dependent deubiquitylation inhibits the nuclear translocation of FOXO4 and decreases its transcriptional activity towards target genes, including the cell cycle arrest gene $C D K N 1 B$ (encoding p27Kip1). Notably, p27Kip1 expression levels are inversely correlated with Pin 1 expression in human primary breast cancer specimens [108], further supporting the idea that Pin1 suppresses p27 expression by inhibiting FOXO transcriptional activity. Pin 1 has also been shown to directly bind to $\mathrm{p} 27 \mathrm{Kip} 1$ at $\mathrm{pT} 187$, which is phosphorylated by cyclin E-CDK2. Pin 1 catalyzes the cis-trans isomerization of p27 and increases p27 stability through regulating its polyubiquitylation $[109,110]$.

The nuclear PML, functioning as a tumor suppressor, regulates apoptosis, viral infection, senescence, DNA damage repair and cell cycle progression. PML protein expression is greatly reduced in many types of cancer cells [111], and $P M L^{-/-}$mice are prone to developing tumors in chemical and physical models of carcinogenesis [112]. The stability of PML is reduced through its interaction with Pin1, in which the four key serine residues (S403, S505, S518 and S527) in the C-terminal half of PML that are phosphorylated in mammalian cells bind to Pin1. ERK2 was identified as a protein kinase phosphorylayting S403 and S505 of PML. SUMOylation of PML blocks the interaction between Pin 1 and PML, thus preventing the degradation of PML. The Pin1-mediated degradation of PML protects breast cancer cells from hydrogen peroxide-induced death and increases their proliferation rates $[113,114]$.

RUNX3 functioning as a tumor suppressor is frequently deleted or transcriptionally silenced in cancer. RUNX3 encodes a member of the runt domain-containing family of transcription factors. RUNX3 and a $\beta$-subunit form a complex that binds to the core DNA sequence $5^{\prime}$-YGYGGT-3', which is found in a number of enhancers and promoters, and this complex can either activate or sup- 
press transcription $[104,115]$. Pin1 interacts with four phosphorylated Ser/Thr-Pro motifs (T209, T212, T231 and S214) in RUNX3 via its WW domain, which results in the ubiquitylation and proteasomal degradation of RUNX3 and suppression of its transcriptional activity [104].

$\mathrm{pRb}$ represses gene expression, and hyperphosphorylation of $\mathrm{pRb}$ releases its inhibition of E2F transcription factors. Pin 1 directly interacts with CDK-phosphorylated $\mathrm{S} 608 / 612$ in the spacer domain of $\mathrm{pRb}$, which enables the interaction between $\mathrm{CDK} /$ cyclin complexes and $\mathrm{pRb}$ in middle and late $\mathrm{G} 1$ phase and promotes pRb S780 phosphorylation. $\mathrm{pRb}$ deficiency abrogates the Pin1 deficiency-induced inhibitory effect on cell proliferation, further supporting the hypothesis that $\mathrm{pRB}$ is a substrate of Pin1 [105, 116].

The tumor suppressor p53 is important in cell cycle arrest or apoptosis in response to a variety of stimuli. In response to DNA damage, p53 interacts with Pin1, and this interaction is dependent on p53 phosphorylation at S33, T81 and S315. The binding of Pin1 to p53 elicits conformational changes in p53 and stimulates its DNA-binding activity and transactivation function towards the $p 21$ promoter. Moreover, Pin1-deficient cells are defective in p53 activation and the timely accumulation of p53 and have impaired checkpoint control in response to DNA damage [117-119]. However, a p53 knock-in mouse model in which the MAPK-phosphorylated and Pin1-targeted T76 and T86 residues in p53 were mutated to Ala, showed only a moderate decrease in p 53 stability and no obvious defects in p53's transactivation or tumor suppressor function $[120,121]$. These results suggest that Pin1-regulated isomerization of the T76-P and T86-P motifs is not instrumental in $\mathrm{p} 53$ 's transcriptional activity. The development of a mouse model for testing the effect of mutations of other potential PIN1-binding sites on $\mathrm{p} 53$ function is warranted.

In response to treatment with doxorubicin and etoposide, Pin 1 induces the mitochondrial translocation and apoptotic activity of $\mathrm{p} 53$, and this translocation is dependent on the homeodomain interacting protein kinase 2 (HIPK2)-mediated phosphorylation of p53 at S46 [122]. Thus, Pin 1 regulates both nuclear and mitochondrial p53 functions in cellular response to genotoxic stress [117119]. In tumor cells lacking functional $\mathrm{p} 53$, chemotherapeutic drug treatment enhances the c-Abl-dependent phosphorylation of the p53-related protein, p73 by p38 MAPK at S412, T442 and T482, which promotes the binding of p73 to Pin1 for p73's subsequent acetylation by $\mathrm{p} 300$. Acetylation of $\mathrm{p} 73$ increases its protein stability and transcriptional activity, and promotes apoptosis [123].

The physiological relationship between Pin1 and p53 was also demonstrated using $P$ in $1^{-/} p 53^{-/-}$mice, which showed that development of lymphomas in p53-deficient mice was inhibited by Pin 1 ablation. In addition, Pin 1 plays an important role in mutant $\mathrm{p} 53$-promoted transformation and metastasis. Pin 1 promotes the mutant p53-dependent inhibition of the anti-metastasis factor p63 and promotes the induction of a mutant p53 transcriptional program to increase tumor aggressiveness. Pin 1 also cooperates with mutant p53 in Ras-dependent transformation to enhance tumorigenesis. Furthermore, in breast cancer patients, the combination of Pin1 overexpression and p53 mutation is an independent prognostic factor for poor clinical outcome [124]. These results suggest that Pin1 impacts p53 function at multiple levels [24].

\section{Pin1 directly regulates proteins involved in apoptosis}

Pin 1 regulates cell apoptosis by directly regulating pro-apoptotic proteins such as B-cell lymphoma 2 (Bcl-2)-associated X protein (BAX) and death-associated protein 6 (Daxx) or anti-apoptotic proteins such as Bcl2 and myeloid cell leukemia-1 (Mcl-1) [3, 103]. Upon stimulation with granulocyte-macrophage colony-stimulating factor, activated ERK1/2 phosphorylates BAX at T167. This phosphorylation facilitates an interaction between BAX and Pin1. Pin1 inhibition leads to the cleavage and mitochondrial translocation of BAX, as well as caspase activation and cell apoptosis [125]. Upon oxidative stress, Daxx is phosphorylated at the Ser178Pro motif, promoting Pin1 binding. Pin1 overexpression results in the rapid degradation of Daxx via the ubiquitin-proteasome pathway, and this degradation may be mediated by a Cul3-based ubiquitin ligase. Depletion of Pin1 significantly enhances the apoptotic response induced by hydrogen peroxide or stimulatory anti-Fas antibodies. In addition, in human glioblastoma, Pin1 expression levels inversely correlate with the degree of Daxx nuclear accumulation, supporting that Pin1 plays an important role in the negative regulation of Daxx [126, 127].

$\mathrm{Bcl}-2$ is an anti-apoptotic oncoprotein. Microtubule-damaging drug-induced phosphorylation of Bcl-2 predominantly occurs at S70 and S87 and is detrimental to the protein's anti-apoptotic function. Phospho-Bcl-2 translocates into the nucleus and interacts with Pin1. Longer Taxol treatment causes proteasomal degradation of Pin1; although Pin1 degradation facilitates the dephosphorylation of $\mathrm{Bcl}-2$, it cannot rescue cells from the already committed apoptotic process [128]. Mcl-1, a Bcl2-like anti-apoptotic protein involved in chemoresistance in several types of human cancer, is also regulated by Pin1. Activated ERK1/2 phosphorylates Mcl-1 at T92 
and $\mathrm{T} 163$, and this phosphorylation is required for the association of Mcl-1 and Pin1, which results in the stabilization of Mcl-1. Inhibition of ERK or depletion of Pin1 sensitizes breast cancer cells to paclitaxel treatment [129]. The anti-apoptotic effect of Pin1 is also related to its regulation of survivin. Pin 1 has been found to interact with the CDC2-phosphorylated Thr34-Pro35 motif of survivin and enhance the association of phosphorylated survivin with pro-caspase-9 and hepatitis B X-interacting protein. Pin 1 overexpression, which suppresses caspase- 3 and caspase-9 activity, has been detected in hepatocellular carcinoma and may play an important role in hepatocarcinogenesis [130]. Thus, Pin1 promotes cell survival by enhancing the function of anti-apoptotic proteins and inhibiting that of pro-apoptotic proteins.

\section{Targeting Pin1 for cancer treatment}

Compelling data suggest that Pin1 can be targeted to treat human cancer. A number of potent Pin1 antagonists have been developed to either inhibit the PPIase activity of Pin1 or target the Pin 1 WW domain to prevent the binding of Pin1 to its substrates [131].

PPIase domain inhibitors identified from enzymatic or cell-based assays include Juglone, PiB [131], dipentamethylenethiuram monosulfide [132] and the halogenated phenylisothiazolone TME-001 [133]. Although these compounds inhibit or inactivate Pin1, questions regarding the specificity of these compounds have been raised, as they can inhibit both the proliferation of Pin1-deficient MEFs and the activity of other cellular targets such as cyclophilin A (which is also inhibited by TME-001) [131]. The use of solid-phase peptide library synthesis and screening of cyclic peptide libraries have revealed that peptidic PPIase inhibitors such as Ac-PheDThr(PO3H2)-Pip-Nal-Gln-NH2 and cyclo(D-Ala-SarD-Thr(PO3H2)-Pip-Nal-Tyr-Gln)-Lys-SH can bind to the Pin1 PPIase domain and inhibit Pin1 activity [131]. Other high-affinity inhibitory peptides such as Ac-Phe1L-(or D-)P.Thr2-Pip3-Nal4 (naphthylalanine)-Gln5- $\mathrm{NH}_{2}$ and Ac-Phe-D-Thr(PO3H2)-Pip-Nal-Gln-NH2, the latter of which specifically blocks HeLa cells in the G2/M phase, were also developed [134, 135]. In addition, small molecules have been derived using structure-based drug design, leading to the development of single-digit-nanomolar Pin1 inhibitors, but, unfortunately, with poor cell permeability [131].

Pin1 WW domain inhibitors bind to the Pin1 WW domain to prevent the binding of Pin1 to its substrates. Epigallocatechin gallate (EGCG), a cancer chemopreventive compound and the major flavonoid in green tea, may bind to both the WW domain and the PPIase domain.
The interaction of EGCG with the Pin1 WW domain involves amino acids implicated in peptide binding and thus should interfere with WW-domain-mediated substrate binding. The binding site for EGCG in the PPIase domain is distinct from the central active site, which suggests that EGCG's inhibition of Pin1 likely occurs via the WW domain [131].

Although a number of potent Pin1 antagonists have been developed, systematic preclinical and clinical studies are needed to evaluate safety and the effect of Pin 1 inhibitors on tumor development. Because Pin1 is positioned to play a general regulatory role in proline-directed kinase signaling and Pin 1 knockout mice exhibit defects in breast development in pregnancy and later have retinal degeneration and neurodegenerative conditions in brain [80,92], Pin1 inhibitors could have many broad-ranging effects. However, since drugs never inhibit their targets completely in vivo, there may be a therapeutic window where Pin 1 inhibitor drugs could be effective, particularly because tumors with elevated levels of Pin 1 are likely to be more dependent on Pin 1 activity than normal cells in the body. Some unwanted neurodegenerative side effects might be alleviated by designing Pin1 inhibitors that fail to cross the blood brain barrier. The successful specific inhibition of Pin1 and its regulators in tumors by compounds or other approaches may offer a new route to efficiently eliminate cancer.

\section{Conclusion}

Accumulating evidence demonstrates that Pin 1 is regulated by different mechanisms at the transcriptional and posttranslational levels and that Pin 1 overexpression is correlated with poor prognosis in several types of human cancers. In addition, the Pin1-mediated cis-trans isomerization of a wide variety of phosphorylated proteins precisely regulates signal transduction from proteins at the plasma membrane to transcription factors and regulators. Thus, Pin1-mediated cis-trans isomerization has profound regulatory effects on many cellular activities, including metabolism, mobility, cell cycle progression, proliferation, survival and apoptosis. The instrumental functions of Pin1 in tumor development make Pin1 a potential target for cancer treatment.

\section{Acknowledgments}

We thank Joe Munch in MD Anderson's Department of Scientific Publications for editing the manuscript and Jong-Ho Lee for preparing the figure and table. This work was supported by the National Institutes of Health through grants 2R01CA109035 (ZL) and 1R0CA169603 (ZL), and MD Anderson's Cancer Center Support Grant CA16672, the Cancer Prevention and Research Institute 
of Texas through grants RP110252 (ZL) and RP130389 (ZL), and the American Cancer Society through Research Scholar Award RSG-09-277-01-CSM (ZL). Research in TH's group is supported by CA14195, CA80100 and CA82683. TH holds the Renato Dulbecco Chair in Cancer Research.

\section{References}

1 Blume-Jensen P, Hunter T. Oncogenic kinase signalling. $\mathrm{Na}$ ture 2001; 411:355-365.

2 Pawson T, Scott JD. Protein phosphorylation in signaling - 50 years and counting. Trends Biochem Sci 2005; 30:286-290.

3 Lee TH, Pastorino L, Lu KP. Peptidyl-prolyl cis-trans isomerase Pin1 in ageing, cancer and Alzheimer disease. Exper Rev mMol mMed 2011; 13:e21.

4 Lu KP, Zhou XZ. The prolyl isomerase PIN1: a pivotal new twist in phosphorylation signalling and disease. Nat Rev Mol Cell Biol 2007; 8:904-916.

5 Gothel SF, Marahiel MA. Peptidyl-prolyl cis-trans isomerases, a superfamily of ubiquitous folding catalysts. Cell Mol Life Sci 1999; 55:423-436.

6 Lu KP, Hanes SD, Hunter T. A human peptidyl-prolyl isomerase essential for regulation of mitosis. Nature 1996; 380:544547.

7 Yaffe MB, Schutkowski M, Shen M, et al. Sequence-specific and phosphorylation-dependent proline isomerization: a potential mitotic regulatory mechanism. Science 1997; 278:1957-1960.

8 Ranganathan R, Lu KP, Hunter T, Noel JP. Structural and functional analysis of the mitotic rotamase Pin1 suggests substrate recognition is phosphorylation dependent. Cell 1997; 89:875-886.

9 Fischer G, Aumuller T. Regulation of peptide bond cis/trans isomerization by enzyme catalysis and its implication in physiological processes. Rev Physiol Biochem Pharmacol 2003; 148:105-150.

10 Finn G, Lu KP. Phosphorylation-specific prolyl isomerase Pin1 as a new diagnostic and therapeutic target for cancer. Curr Cancer Drug Targets 2008; 8:223-229.

11 Pastorino L, Sun A, Lu PJ, et al. The prolyl isomerase Pin1 regulates amyloid precursor protein processing and amyloid-beta production. Nature 2006; 440:528-534.

12 Zhou XZ, Kops O, Werner A, et al. Pin1-dependent prolyl isomerization regulates dephosphorylation of $\mathrm{Cdc} 25 \mathrm{C}$ and tau proteins. Mol Cell 2000; 6:873-883.

13 Werner-Allen JW, Lee CJ, Liu P, et al. cis-Proline-mediated $\operatorname{Ser}(\mathrm{P}) 5$ dephosphorylation by the RNA polymerase II C-terminal domain phosphatase Ssu72. J Biol Chem 2011; 286:5717-5726.

14 Xiang K, Nagaike T, Xiang S, et al. Crystal structure of the human symplekin-Ssu72-CTD phosphopeptide complex. $\mathrm{Na}$ ture 2010; 467:729-733.

15 Zhang M, Wang XJ, Chen X, et al. Structural and kinetic analysis of prolyl-isomerization/phosphorylation cross-talk in the CTD code. ACS Chem Biol 2012; 7:1462-1470.

16 Welcker M, Orian A, Jin J, et al. The Fbw7 tumor suppressor regulates glycogen synthase kinase 3 phosphorylation-dependent c-Myc protein degradation. Proc Natl Acad Sci USA 2004; 101:9085-9090.
17 Yeh E, Cunningham M, Arnold $\mathrm{H}$, et al. A signalling pathway controlling c-Myc degradation that impacts oncogenic transformation of human cells. Nat Cell Biol 2004; 6:308-318.

18 Yeh ES, Lew BO, Means AR. The loss of PIN1 deregulates cyclin $\mathrm{E}$ and sensitizes mouse embryo fibroblasts to genomic instability. J Biol Chem 2006; 281:241-251.

19 Ryo A, Suizu F, Yoshida Y, et al. Regulation of NF-kappaB signaling by Pin1-dependent prolyl isomerization and ubiquitin-mediated proteolysis of p65/RelA. Mol Cell 2003; 12:1413-1426.

20 De Nicola F, Bruno T, Iezzi S, et al. The prolyl isomerase Pin1 affects Che-1 stability in response to apoptotic DNA damage. J Biol Chem 2007; 282:19685-19691.

21 Nakamura K, Greenwood A, Binder L, et al. Proline isomer-specific antibodies reveal the early pathogenic tau conformation in Alzheimer's disease. Cell 2012; 149:232-244.

22 Suizu F, Ryo A, Wulf G, Lim J, Lu KP. Pin1 regulates centrosome duplication, and its overexpression induces centrosome amplification, chromosome instability, and oncogenesis. Mol Cell Biol 2006; 26:1463-1479.

23 Wulf G, Garg P, Liou YC, Iglehart D, Lu KP. Modeling breast cancer in vivo and ex vivo reveals an essential role of Pin1 in tumorigenesis. EMBO J 2004; 23:3397-3407.

24 Takahashi K, Akiyama H, Shimazaki K, et al. Ablation of a peptidyl prolyl isomerase Pin1 from p53-null mice accelerated thymic hyperplasia by increasing the level of the intracellular form of Notch1. Oncogene 2007; 26:3835-3845.

25 Bao L, Kimzey A, Sauter G, Sowadski JM, Lu KP, Wang DG. Prevalent overexpression of prolyl isomerase Pin1 in human cancers. Am J Pathol 2004; 164:1727-1737.

26 Wulf GM, Ryo A, Wulf GG, et al. Pin1 is overexpressed in breast cancer and cooperates with Ras signaling in increasing the transcriptional activity of c-Jun towards cyclin D1. EMBO $J$ 2001; 20:3459-3472.

27 Ayala G, Wang D, Wulf G, et al. The prolyl isomerase Pin1 is a novel prognostic marker in human prostate cancer. Cancer Res 2003; 63:6244-6251.

28 Sasaki T, Ryo A, Uemura H, et al. An immunohistochemical scoring system of prolyl isomerase Pin1 for predicting relapse of prostate carcinoma after radical prostatectomy. Pathol Res Pract 2006; 202:357-364.

29 Tan X, Zhou F, Wan J, et al. Pin1 expression contributes to lung cancer: Prognosis and carcinogenesis. Cancer Biol Ther 2010; 9:111-119.

30 Leung $\mathrm{KW}$, Tsai $\mathrm{CH}$, Hsiao $\mathrm{M}$, et al. Pin1 overexpression is associated with poor differentiation and survival in oral squamous cell carcinoma. Oncol Rep 2009; 21:1097-1104.

31 He J, Zhou F, Shao K, et al. Overexpression of Pin1 in nonsmall cell lung cancer (NSCLC) and its correlation with lymph node metastases. Lung Cancer 2007; 56:51-58.

32 Miyashita H, Mori S, Motegi K, Fukumoto M, Uchida T. Pin1 is overexpressed in oral squamous cell carcinoma and its levels correlate with cyclin D1 overexpression. Oncol Rep 2003; 10:455-461.

33 Miyashita H, Uchida T, Mori S, Echigo S, Motegi K. Expression status of Pin1 and cyclins in oral squamous cell carcinoma: Pin1 correlates with Cyclin D1 mRNA expression and clinical significance of cyclins. Oncol Rep 2003; 10:10451048 . 
34 Ryo A, Liou YC, Wulf G, Nakamura M, Lee SW, Lu KP. PIN1 is an E2F target gene essential for Neu/Ras-induced transformation of mammary epithelial cells. Mol Cell Biol 2002; 22:5281-5295.

35 Lee KY, Lee JW, Nam HJ, Shim JH, Song Y, Kang KW. PI3-kinase/p38 kinase-dependent E2F1 activation is critical for Pin1 induction in tamoxifen-resistant breast cancer cells. Mol Cell 2011; 32:107-111.

$36 \mathrm{Lu} \mathrm{J}, \mathrm{Hu} \mathrm{Z}$, Wei S, et al. A novel functional variant $(-842 \mathrm{G}>\mathrm{C})$ in the PIN1 promoter contributes to decreased risk of squamous cell carcinoma of the head and neck by diminishing the promoter activity. Carcinogenesis 2009; 30:1717-1721.

37 Li Q, Dong Z, Lin Y, et al. The rs2233678 Polymorphism in PIN1 Promoter Region Reduced Cancer Risk: A Meta-Analysis. PloS One 2013; 8: 68148.

38 Ma SL, Tang NL, Tam CW, et al. A PIN1 polymorphism that prevents its suppression by AP4 associates with delayed onset of Alzheimer's disease. Neurobiol Aging 2012; 33:804-813.

39 Lee $\mathrm{TH}$, Chen $\mathrm{CH}$, Suizu F, et al. Death-associated protein kinase 1 phosphorylates Pin 1 and inhibits its prolyl isomerase activity and cellular function. Mol Cell 2011; 42:147-159.

40 Rangasamy V, Mishra R, Sondarva G, et al. Mixed-lineage kinase 3 phosphorylates prolyl-isomerase Pin1 to regulate its nuclear translocation and cellular function. Proc Natl Acad Sci USA 2012; 109:8149-8154.

41 Eckerdt F, Yuan J, Saxena K, et al. Polo-like kinase 1-mediated phosphorylation stabilizes Pin1 by inhibiting its ubiquitination in human cells. J Biol Chem 2005; 280:36575-36583.

42 Lu PJ, Zhou XZ, Liou YC, Noel JP, Lu KP. Critical role of WW domain phosphorylation in regulating phosphoserine binding activity and Pin1 function. J Biol Chem 2002; 277:2381-2384.

43 Cho YS, Park SY, Kim DJ, et al. TPA-induced cell transformation provokes a complex formation between Pin 1 and 90 kDa ribosomal protein S6 kinase 2. Mol Cell Biochem 2012; 367:85-92.

44 Aluise CD, Rose K, Boiani M, et al. Peptidyl-prolyl cis/ trans-isomerase A1 (Pin1) is a target for modification by lipid electrophiles. Chem Res Toxicol 2013; 26:270-279.

45 Chen $\mathrm{CH}$, Chang CC, Lee TH, et al. SENP1 deSUMOylates and Regulates Pin1 Protein Activity and Cellular Function. Cancer Res 2013; 73:3951-3962.

46 Yang W, Zheng Y, Xia Y, et al. ERK1/2-dependent phosphorylation and nuclear translocation of PKM2 promotes the Warburg effect. Nat Cell Biol 2012; 14:1295-1304.

47 Yang W, Xia Y, Cao Y, et al. EGFR-induced and PKCepsilon monoubiquitylation-dependent NF-kappaB activation upregulates PKM2 expression and promotes tumorigenesis. Mol Cell 2012; 48:771-784.

48 Yang W, Xia Y, Ji H, et al. Nuclear PKM2 regulates beta-catenin transactivation upon EGFR activation. Nature 2011; 480:118-122.

49 Yang W, Lu Z. Nuclear PKM2 regulates the Warburg effect. Cell Cycle 2013; 12:3154-3158.

$50 \mathrm{Lu} \mathrm{Z}$. Nonmetabolic functions of pyruvate kinase isoform M2 in controlling cell cycle progression and tumorigenesis. Chinese J Cancer 2012; 31:5-7.

51 Yang W, Xia Y, Hawke D, et al. PKM2 phosphorylates histone $\mathrm{H} 3$ and promotes gene transcription and tumorigenesis. Cell
2012; 150:685-696

52 Lu Z. PKM2 functions as a histone kinase. Cell Cycle 2012; 11:4101-4102.

$53 \mathrm{Lu} \mathrm{Z}$, Hunter T. Degradation of activated protein kinases by ubiquitination. Ann Rev Biochem 2009; 78:435-475.

54 Lam PB, Burga LN, Wu BP, Hofstatter EW, Lu KP, Wulf GM. Prolyl isomerase Pin 1 is highly expressed in Her2-positive breast cancer and regulates erbB2 protein stability. Mol Cancer 2008; 7:91.

55 Rustighi A, Tiberi L, Soldano A, et al. The prolyl-isomerase Pin1 is a Notch1 target that enhances Notch1 activation in cancer. Nat Cell Biol 2009; 11:133-142.

56 Rustighi A, Zannini A, Tiberi L, et al. Prolyl-isomerase Pin1 controls normal and cancer stem cells of the breast. EMBO Mol Med 2014; 6:99-119.

57 Zheng Y, Lu Z. Paradoxical roles of FAK in tumor cell migration and metastasis. Cell Cycle 2009; 8:3474-3479.

58 Zheng Y, Xia Y, Hawke D, et al. FAK phosphorylation by ERK primes ras-induced tyrosine dephosphorylation of FAK mediated by PIN1 and PTP-PEST. Mol Cell 2009; 35:11-25.

59 Lu Z, Jiang G, Blume-Jensen P, Hunter T. Epidermal growth factor-induced tumor cell invasion and metastasis initiated by dephosphorylation and downregulation of focal adhesion kinase. Mol Cell Biol 2001; 21:4016-4031.

60 Zheng Y, Yang W, Xia Y, Hawke D, Liu DX, Lu Z. Ras-induced and extracellular signal-regulated kinase 1 and 2 phosphorylation-dependent isomerization of protein tyrosine phosphatase (PTP)-PEST by PIN1 promotes FAK dephosphorylation by PTP-PEST. Mol CellBiol 2011; 31:4258-4269.

61 Zheng Y, Lu Z. Regulation of tumor cell migration by protein tyrosine phosphatase (PTP)-proline-, glutamate-, serine-, and threonine-rich sequence (PEST). Chinese J Cancer 2013; 32:75-83.

62 Dougherty MK, Muller J, Ritt DA, et al. Regulation of Raf-1 by direct feedback phosphorylation. Mol Cell 2005; 17:215224.

63 Khanal P, Namgoong GM, Kang BS, Woo ER, Choi HS. The prolyl isomerase Pin1 enhances HER-2 expression and cellular transformation via its interaction with mitogen-activated protein kinase/extracellular signal-regulated kinase kinase 1 . Mol Cancer Ther 2010; 9:606-616.

64 Park JE, Lee JA, Park SG, et al. A critical step for JNK activation: isomerization by the prolyl isomerase Pin1. Cell Death Differ 2012; 19:153-161.

65 Liao Y, Wei Y, Zhou X, et al. Peptidyl-prolyl cis/trans isomerase Pin1 is critical for the regulation of PKB/Akt stability and activation phosphorylation. Oncogene 2009; 28:2436-2445.

66 Lee NY, Choi HK, Shim JH, Kang KW, Dong Z, Choi HS. The prolyl isomerase Pin1 interacts with a ribosomal protein S6 kinase to enhance insulin-induced AP-1 activity and cellular transformation. Carcinogenesis 2009; 30:671-681.

67 Penela P, Rivas V, Salcedo A, Mayor F, Jr. G protein-coupled receptor kinase 2 (GRK2) modulation and cell cycle progression. Proc Natl Acad Sci USA 2010; 107:1118-1123.

68 Wells NJ, Watanabe N, Tokusumi T, Jiang W, Verdecia MA, Hunter T. The C-terminal domain of the Cdc2 inhibitory kinase Myt1 interacts with $\mathrm{Cdc} 2$ complexes and is required for inhibition of G(2)/M progression. J Cell Sci 1999; 112:33613371. 
69 Crenshaw DG, Yang J, Means AR, Kornbluth S. The mitotic peptidyl-prolyl isomerase, Pin1, interacts with Cdc25 and Plx1. EMBO J 1998; 17:1315-1327.

70 Kumagai A, Dunphy WG. Purification and molecular cloning of Plx1, a Cdc25-regulatory kinase from Xenopus egg extracts. Science 1996; 273:1377-1380.

71 Stukenberg PT, Kirschner MW. Pin1 acts catalytically to promote a conformational change in Cdc25. Mol Cell 2001; 7:1071-1083.

72 Guen VJ, Gamble C, Flajolet M, et al. CDK10/cyclin M is a protein kinase that controls ETS2 degradation and is deficient in STAR syndrome. Proc Natl Acad Sci USA 2013; 110:19525-19530.

73 Iorns E, Turner NC, Elliott R, et al. Identification of CDK10 as an important determinant of resistance to endocrine therapy for breast cancer. Cancer Cell 2008; 13:91-104.

74 Khanal P, Yun HJ, Lim SC, et al. Proyl isomerase Pin1 facilitates ubiquitin-mediated degradation of cyclin-dependent kinase 10 to induce tamoxifen resistance in breast cancer cells. Oncogene 2012; 31:3845-3856.

75 Khanal P, Kim G, Lim SC, et al. Prolyl isomerase Pin1 negatively regulates the stability of SUV39H1 to promote tumorigenesis in breast cancer. FASEB J 2013; 27:4606-4618.

76 Keune WJ, Jones DR, Bultsma Y, et al. Regulation of phosphatidylinositol-5-phosphate signaling by Pin 1 determines sensitivity to oxidative stress. Sci Signal 2012; 5:ra86.

77 Min SH, Lau AW, Lee TH, et al. Negative regulation of the stability and tumor suppressor function of Fbw7 by the Pin1 prolyl isomerase. Mol Cell 2012; 46:771-783.

78 van Drogen F, Sangfelt O, Malyukova A, et al. Ubiquitylation of cyclin $\mathrm{E}$ requires the sequential function of SCF complexes containing distinct hCdc4 isoforms. Mol Cell 2006; 23:37-48.

79 Steger M, Murina O, Huhn D, et al. Prolyl isomerase PIN1 regulates DNA double-strand break repair by counteracting DNA end resection. Mol Cell 2013; 50:333-343.

80 Liou YC, Ryo A, Huang HK, et al. Loss of Pin1 function in the mouse causes phenotypes resembling cyclin D1-null phenotypes. Proc Natl Acad Sci USA 2002; 99:1335-1340.

81 Diehl JA, Cheng M, Roussel MF, Sherr CJ. Glycogen synthase kinase-3beta regulates cyclin D1 proteolysis and subcellular localization. Genes Dev 1998; 12:3499-3511.

82 Ryo A, Nakamura M, Wulf G, Liou YC, Lu KP. Pin1 regulates turnover and subcellular localization of beta-catenin by inhibiting its interaction with APC. Nat Cell Biol 2001; 3:793-801.

83 Pulikkan JA, Dengler V, Peer Zada AA, et al. Elevated PIN1 expression by C/EBPalpha-p30 blocks C/EBPalpha-induced granulocytic differentiation through c-Jun in AML. Leukemia 2010; 24:914-923.

84 Monje P, Hernandez-Losa J, Lyons RJ, Castellone MD, Gutkind JS. Regulation of the transcriptional activity of c-Fos by ERK. A novel role for the prolyl isomerase PIN1. J Biol Chem 2005; 280:35081-35084.

85 Fan G, Fan Y, Gupta N, et al. Peptidyl-prolyl isomerase Pin1 markedly enhances the oncogenic activity of the rel proteins in the nuclear factor-kappaB family. Cancer Res 2009; 69:4589-4597.

86 Minella AC, Welcker M, Clurman BE. Ras activity regulates cyclin E degradation by the Fbw7 pathway. Proc Natl Acad Sci USA 2005; 102:9649-9654.
87 Farrell AS, Pelz C, Wang X, et al. Pin1 Regulates the Dynamics of c-Myc DNA Binding To Facilitate Target Gene Regulation and Oncogenesis. Mol Cell Biol 2013; 33:2930-2949.

88 Gregory MA, Qi Y, Hann SR. Phosphorylation by glycogen synthase kinase-3 controls c-myc proteolysis and subnuclear localization. J Biol Chem 2003; 278:51606-51612.

89 Arnold HK, Zhang X, Daniel CJ, et al. The Axin1 scaffold protein promotes formation of a degradation complex for c-Myc. EMBO J 2009; 28:500-512.

90 Pani E, Menigatti M, Schubert S, et al. Pin1 interacts with $\mathrm{c}-\mathrm{Myb}$ in a phosphorylation-dependent manner and regulates its transactivation activity. Biochim Biophys Acta 2008; 1783:1121-1128.

91 Luo Z, Wijeweera A, Oh Y, Liou YC, Melamed P. Pin1 facilitates the phosphorylation-dependent ubiquitination of SF-1 to regulate gonadotropin beta-subunit gene transcription. $\mathrm{Mol}$ Cell Biol 2010; 30:745-763.

92 Fujimori F, Takahashi K, Uchida C, Uchida T. Mice lacking Pin1 develop normally, but are defective in entering cell cycle from $\mathrm{G}(0)$ arrest. Biochem Biophys Res Commun 1999; 265:658-663.

93 Atchison FW, Means AR. Spermatogonial depletion in adult Pin1-deficient mice. Biol Reprod 2003; 69:1989-1997.

94 Nishi M, Akutsu H, Masui S, et al. A distinct role for Pin1 in the induction and maintenance of pluripotency. $J$ Biol Chem 2011; 286:11593-11603.

95 Moretto-Zita M, Jin H, Shen Z, Zhao T, Briggs SP, Xu Y. Phosphorylation stabilizes Nanog by promoting its interaction with Pin1. Proc Natl Acad Sci USA 2010; 107:13312-13317.

96 Lufei C, Koh TH, Uchida T, Cao X. Pin1 is required for the Ser727 phosphorylation-dependent Stat3 activity. Oncogene 2007; 26:7656-7664.

97 Wierod L, Rosseland CM, Lindeman B, et al. CDK2 regulation through PI3K and CDK4 is necessary for cell cycle progression of primary rat hepatocytes. Cell Proliferation 2007; 40:475-487.

98 Lucchetti C, Caligiuri I, Toffoli G, Giordano A, Rizzolio F. The prolyl isomerase Pin 1 acts synergistically with CDK2 to regulate the basal activity of estrogen receptor alpha in breast cancer. PloS One 2013; 8:e55355.

99 Lannigan DA. Estrogen receptor phosphorylation. Steroids 2003; 68:1-9.

100 Rajbhandari P, Schalper KA, Solodin NM, et al. Pin1 modulates ERalpha levels in breast cancer through inhibition of phosphorylation-dependent ubiquitination and degradation. Oncogene 2013; 33:1438-1447.

101 Rajbhandari P, Finn G, Solodin NM, et al. Regulation of estrogen receptor alpha N-terminus conformation and function by peptidyl prolyl isomerase Pin1. Mol Cell Biol 2012; 32:445-457.

102 Yi P, Wu RC, Sandquist J, et al. Peptidyl-prolyl isomerase 1 (Pin1) serves as a coactivator of steroid receptor by regulating the activity of phosphorylated steroid receptor coactivator 3 (SRC-3/AIB1). Mol Cell Biol 2005; 25:9687-9699.

103 Liou YC, Zhou XZ, Lu KP. Prolyl isomerase Pin1 as a molecular switch to determine the fate of phosphoproteins. Trends Biochem Sci 2011; 36:501-514.

104 Nicole Tsang YH, Wu XW, Lim JS, et al. Prolyl isomerase Pin1 downregulates tumor suppressor RUNX3 in breast can- 
cer. Oncogene 2013; 32:1488-1496.

105 Rizzolio F, Lucchetti C, Caligiuri I, et al. Retinoblastoma tumor-suppressor protein phosphorylation and inactivation depend on direct interaction with Pin1. Cell Death Differ 2012; 19:1152-1161.

106 Nakano A, Koinuma D, Miyazawa K, et al. Pin1 down-regulates transforming growth factor-beta (TGF-beta) signaling by inducing degradation of Smad proteins. J Biol Chem 2009; 284:6109-6115.

107 Stanya KJ, Liu Y, Means AR, Kao HY. Cdk2 and Pin1 negatively regulate the transcriptional corepressor SMRT. $J$ Cell Biol 2008; 183:49-61.

108 Brenkman AB, de Keizer PL, van den Broek NJ, et al. The peptidyl-isomerase Pin1 regulates p27kip1 expression through inhibition of Forkhead box O tumor suppressors. Cancer Res 2008; 68:7597-7605.

109 Zhou W, Yang Q, Low CB, et al. Pin1 catalyzes conformational changes of Thr-187 in p27Kip1 and mediates its stability through a polyubiquitination process. J Biol Chem 2009; 284:23980-23988.

110 Sheaff RJ, Groudine M, Gordon M, Roberts JM, Clurman BE. Cyclin E-CDK2 is a regulator of p27Kip1. Genes Dev 1997; 11:1464-1478.

111 Gurrieri C, Capodieci P, Bernardi R, et al. Loss of the tumor suppressor PML in human cancers of multiple histologic origins. J Natl Cancer Inst 2004; 96:269-279.

112 Wang ZG, Delva L, Gaboli M, et al. Role of PML in cell growth and the retinoic acid pathway. Science 1998; 279:1547-1551.

113 Reineke EL, Lam M, Liu Q, et al. Degradation of the tumor suppressor PML by Pin1 contributes to the cancer phenotype of breast cancer MDA-MB-231 cells. Mol Cell Biol 2008; 28:997-1006.

114 Lim JH, Liu Y, Reineke E, Kao HY. Mitogen-activated protein kinase extracellular signal-regulated kinase 2 phosphorylates and promotes Pin 1 protein-dependent promyelocytic leukemia protein turnover. J Biol Chem 2011; 286:44403-44411.

115 Levanon D, Eisenstein M, Groner Y. Site-directed mutagenesis supports a three-dimensional model of the runt domain. $J$ Mol Biol 1998; 277:509-512.

116 Rizzolio F, Caligiuri I, Lucchetti C, et al. Dissecting Pin1 and phospho-pRb regulation. J Cell Physiol 2013; 228:73-77.

117 Zheng H, You H, Zhou XZ, et al. The prolyl isomerase Pin1 is a regulator of p53 in genotoxic response. Nature 2002; 419:849-853.

118 Zacchi P, Gostissa M, Uchida T, et al. The prolyl isomerase Pin1 reveals a mechanism to control p53 functions after genotoxic insults. Nature 2002; 419:853-857.

119 Wulf GM, Liou YC, Ryo A, Lee SW, Lu KP. Role of Pin1 in the regulation of $\mathrm{p} 53$ stability and $\mathrm{p} 21$ transactivation, and cell cycle checkpoints in response to DNA damage. $J$ Biol Chem 2002; 277:47976-47979.

120 Toledo F, Lee CJ, Krummel KA, Rodewald LW, Liu CW, Wahl GM. Mouse mutants reveal that putative protein inter- action sites in the $\mathrm{p} 53$ proline-rich domain are dispensable for tumor suppression. Mol Cell Biol 2007; 27:1425-1432.

121 Milne DM, Campbell DG, Caudwell FB, Meek DW. Phosphorylation of the tumor suppressor protein p53 by mitogen-activated protein kinases. J Biol Chem 1994; 269:92539260.

122 Sorrentino G, Mioni M, Giorgi C, et al. The prolyl-isomerase Pin1 activates the mitochondrial death program of p53. Cell Death Differ 2013; 20:198-208.

123 Mantovani F, Piazza S, Gostissa M, et al. Pin1 links the activities of c-Abl and p300 in regulating p73 function. Mol Cell 2004; 14:625-636.

124 Girardini JE, Napoli M, Piazza S, et al. A Pin1/mutant p53 axis promotes aggressiveness in breast cancer. Cancer Cell 2011; 20:79-91.

125 Shen ZJ, Esnault S, Schinzel A, Borner C, Malter JS. The peptidyl-prolyl isomerase Pin 1 facilitates cytokine-induced survival of eosinophils by suppressing Bax activation. Nat Immunol 2009; 10:257-265.

126 Ryo A, Hirai A, Nishi M, et al. A suppressive role of the prolyl isomerase Pin1 in cellular apoptosis mediated by the death-associated protein Daxx. J Biol Chem 2007; 282:36671-36681.

127 Kwon JE, La M, Oh KH, et al. BTB domain-containing speckle-type POZ protein (SPOP) serves as an adaptor of Daxx for ubiquitination by Cul3-based ubiquitin ligase. $\mathrm{J}$ Biol Chem 2006; 281:12664-12672.

128 Basu A, Das M, Qanungo S, Fan XJ, DuBois G, Haldar S. Proteasomal degradation of human peptidyl prolyl isomerase pin1-pointing phospho Bcl2 toward dephosphorylation. Neoplasia 2002; 4:218-227.

129 Ding Q, Huo L, Yang JY, et al. Down-regulation of myeloid cell leukemia-1 through inhibiting Erk/Pin 1 pathway by sorafenib facilitates chemosensitization in breast cancer. Cancer Res 2008; 68:6109-6117.

130 Cheng CW, Chow AK, Pang R, Fok EW, Kwong YL, Tse E. PIN1 inhibits apoptosis in hepatocellular carcinoma through modulation of the antiapoptotic function of survivin. $\mathrm{Am} \mathrm{J}$ Pathol 2013; 182:765-775.

131 Moore JD, Potter A. Pin1 inhibitors: Pitfalls, progress and cellular pharmacology. Bioorg Med Chem Lett 2013; 23:42834291.

132 Lu KP, Finn G, Lee TH, Nicholson LK. Prolyl cis-trans isomerization as a molecular timer. Nat Chem Biol 2007; 3:619-629.

133 Rahfeld JU, Rucknagel KP, Schelbert B, et al. Confirmation of the existence of a third family among peptidyl-prolyl cis/trans isomerases. Amino acid sequence and recombinant production of parvulin. FEBS Lett 1994; 352:180-184.

134 Wildemann D, Erdmann F, Alvarez BH, et al. Nanomolar inhibitors of the peptidyl prolyl cis/trans isomerase Pin 1 from combinatorial peptide libraries. J Med Chem 2006; 49:21472150.

135 Zhang Y, Daum S, Wildemann D, et al. Structural basis for high-affinity peptide inhibition of human Pin1. ACS Chem Biol 2007; 2:320-328. 